DíAz Gómez, A., «Novedades del Proyecto de reforma de 2013 del Código Penal sobre la responsabilidad de las personas jurídicas», REDUR II, diciembre 20I3, págs. I49-167. ISSN ı695-078X

\title{
NOVEDADES DEL PROYECTO DE REFORMA DE 2OI3 DEL Código PENAL SOBRE LA RESPONSABILIDAD DE LAS PERSONAS JURÍDICAS*
}

\author{
Andrés DíAz GÓMEZ \\ INVESTIGADOR FPU \\ UNIVERSIDAD DE LA RIOJA
}

SuMARIO: I. Introducción; II. La capacidad de responsabilidad de las personas jurídicas; III. La «doble vía» de responsabilidad; IV. El nuevo delito de incumplimiento del deber de vigilancia o control en personas jurídicas y empresas: su incidencia en el sistema de atribución de responsabilidad a las personas jurídicas; V. Los delitos susceptibles de comisión por las personas jurídicas; VI. Cancelación de penas y antecedentes; VII. Circunstancias modificativas de la responsabilidad; VIII. Un nuevo impulso a la autorregulación: la importancia de los modelos de prevención empresarial como exención de responsabilidad de las personas jurídicas; IX. Bibliografía citada.

RESUMEN: La Ley Orgánica 5/2010 supuso un cambio de paradigma en lo que respecta a la responsabilidad penal de las personas jurídicas en el Derecho español, introduciendo en el Código Penal un auténtico modelo societas delinquere potest. En estos momentos se planea una nueva reforma del Código Penal, que previsiblemente introducirá importantes modificaciones sobre el sistema de responsabilidad de las personas jurídicas ya existente, destacando la potenciación de los llamados programas de cumplimiento empresarial como forma de exención de responsabilidad criminal. Este trabajo analiza brevemente las novedades propuestas en 2013 por el Proyecto de Ley Orgánica de reforma del Código Penal en este ámbito.

PALABRAS ClAVE: personas jurídicas, responsabilidad penal de las personas jurídicas, programas de cumplimiento.

ABSTRACT: The Spanish Organic Law 5/20Io set up a paradigm shift with regard to the criminal liability of legal entities in the Spanish Law, by introducing into the Penal Code the principle societas delinquere potest. At present a new reform is planned in the Penal Code, which is expected to introduce important changes into the already existing system of liability of legal entities, highlighting the strengthening of so-called corporate compliance programs as a form of exculpatory circumstances of criminal responsibility. This paper briefly analyses the changes proposed by the Draft Organic Law at 2013 amending the Penal Code in this field.

KEYWORDS: legal entities, corporate criminal liability, compliance programs.

\footnotetext{
* Este trabajo se ha elaborado en el marco del Programa FPU del Ministerio de Educación, Cultura y Deporte.
} 


\section{Introducción}

La posibilidad de que una persona jurídica sea criminalmente responsable es muy reciente en el tiempo en nuestro Derecho penal. Hasta la aprobación de la LO 5/2010 por la que se modificó el Código Penal, que entraría en vigor a finales del año 2010, no se instauraría definitivamente el dogma societas delinquere postest en nuestro país. Esta norma supondría, por tanto, un cambio de paradigma en lo referente al sistema de responsabilidad penal de las personas jurídicas. De un modelo basado en el principio societas delinquere non potest se pasó a otro en el que, a partir de un modelo mixto de imputación, se asume la responsabilidad penal de determinadas entidades con personalidad jurídica, y por consiguiente, la posibilidad de imponerles sanciones penales.

La aparición de nuestro actual sistema de atribución de responsabilidad criminal a las personas jurídicas ha sido objeto de importantes disquisiciones doctrinales, así como de una creciente evolución hasta la llegada de la LO 5/2010, que comenzaría con la aprobación de nuestro vigente Código Penal ${ }^{1}$. Pero una vez superado, por la LO 5/20IO, el tradicional modelo de responsabilidad individual (personas físicas), al combinarse con un auténtico sistema de responsabilidad penal de personas jurídicas, las posteriores reformas del Código Penal debían, teóricamente, tratar de perfeccionar ese sistema.

A esa finalidad responde, aparentemente, el Proyecto de Ley Orgánica por la que se modifica la Ley Orgánica Io/1995, de 23 de noviembre, del Código Penal, presentado por el Gobierno ante el Congreso el día 2I de septiembre de 20I3. De acuerdo con su Exposición de Motivos: «Se introduce una mejora técnica en la regulación de la responsabilidad penal de las personas jurídicas, introducida en nuestro ordenamiento jurídico por la Ley Orgánica 5/2010, de 22 de junio, con la finalidad de delimitar adecuadamente el contenido del «debido control», cuyo quebrantamiento permite fundamentar su responsabilidad penal».

El proyecto prevé diversas novedades de distinto calado en lo que respecta al sistema de responsabilidad instaurado por la LO 5/2010, destacando especialmente la modificación

\footnotetext{
'Ya en el Código de I995, el art. 3I que recoge la cláusula «actuar en nombre de otro» o las consecuencias accesorias del antiguo art. I29 del Código Penal dieron lugar a que algunos autores afirmaran que esos preceptos instauraban un auténtico sistema de responsabilidad penal de las personas jurídicas. Aunque como afirmó, entre otros, ZUGALDÍA ESPINAR, «...el artículo 3і C.p no guarda ninguna relación, en absoluto, con el tema de la responsabilidad criminal de las personas jurídicas (!): es más, un Derecho penal que admitiera plenamente la responsabilidad de las personas jurídicas debería contener, de todos modos, una previsión expresa de las actuaciones en nombre de otro» (ZUGALDÍA ESPINAR, J.M., «Artículo 3I», en COBO DEL ROSAL, M. (dir.), Comentarios al Código Penal, tomo III, Madrid, Edersa, 2000, pág. 4IG). Respecto de las consecuencias del art. I29, si bien su naturaleza jurídica suscitó en su momento muchas opiniones divergentes, la mayoría de la doctrina rehusaba considerarlas como «penas» en el sentido de responsabilidad penal de las personas jurídicas (vid. respecto de las distintas concepciones, GUARDIOLA LAGO, M.J., Responsabilidad penal de las personas jurídicas y alcance del art. 129 del Código penal, Valencia, Tirant lo Blanch, 2004, págs. 80 ss.). Más adelante, con la introducción del art. 3I.2 CP por la LO I5/2003 (hoy derogado), se planteó también la posibilidad de que tal precepto recogiera una auténtica responsabilidad criminal de las personas jurídicas, pues, como rezaba textualmente la exposición de motivos de dicha Ley, parte II, $1 .:$ «Se aborda la responsabilidad penal de las personas jurídicas». No era esa sin embargo la opinión de la doctrina, que afirmó en mayoría que no cabía inferir la pérdida de la vigencia del principio societas delinquere non potest de acuerdo con este precepto (por todos, MIR PUIG, S. y ALCÁCER GUIRAO, R., «Cambio de orientación en la política criminal española: últimas reformas del código penal», en GÓMEZ MARTÍN, V. (coord.), Política criminal y reforma penal, Madrid, Edisofer, 2007, págs. II3 y II4).

Sobre todas estas cuestiones puede verse resumidamente nuestro trabajo titulado «La Responsabilidad Criminal de las Personas Jurídicas en el Derecho Español», en línea, disponible en Internet: www.epol.com.ar/newsmatic/index.php?pub_id=72I\&sid=6780\&NombreSeccion=Difusi\%F3n\&Accion=VerArticulo\& aid=70043\&eid=I, págs. I5 a 39 .
} 
del artículo 3r.bis del Código Penal para introducir referencias explícitas a los llamados programas de cumplimiento o de autorregulación. A continuación se examinarán las modificaciones que experimentará el Código Penal de aprobarse en las Cortes Generales esta nueva Ley Orgánica, haciendo especial hincapié en las cuestiones que creemos que son más importantes. Téngase en cuenta que la reforma también plantea algunas modificaciones de menor importancia relativas a la sistemática y recolocación de preceptos ya existentes a los que no se hará referencia en los siguientes apartados; tales son las vicisitudes que plantean las relaciones entre el delito cometido por la persona física y la persona jurídica ${ }^{2}$ y el catálogo de penas previstas ${ }^{3}$.

\section{La capacidad de responsabilidad de las personas jurídicas}

El sistema de responsabilidad penal de las personas jurídicas establecido por la LO 5/2010 hacía recaer tal responsabilidad, como es natural, sobre aquellas organizaciones o entidades dotadas de personalidad jurídica. Pero no nos detendremos en un concepto tan abstruso y polisémico como es el de «personalidad jurídica». Lo que interesa destacar es que, inicialmente, el artículo 3I.5 CP recogía que las disposiciones relativas a la responsabilidad penal de las personas jurídicas no eran aplicables al Estado, las Administraciones Públicas territoriales e institucionales, los Organismos Reguladores, las Agencias y Entidades Públicas Empresariales, los partidos políticos, los sindicatos o la sociedades mercantiles estatales que ejecuten políticas públicas o presten servicios de interés económico general, entre otras. Esto significa que estas entidades carecen de responsabilidad penal conforme a nuestra legislación ${ }^{4}$.

Posteriormente, la LO 7/2OI2 elimina de este precepto a los partidos políticos y a los sindicatos, incluyéndolos en el régimen general de responsabilidad penal, superando así «la percepción de impunidad de estos dos actores de la vida política que trasladaba la anterior regulación», en los términos de la Exposición de Motivos de la Mencionada Ley5.

\footnotetext{
${ }^{2}$ Estas cuestiones, que se recogen conforme a la LO 5/2010 en el artículo 3r.bis apartados 2 y 3, pasan al nuevo artículo 3I.ter. Este precepto recogería la posibilidad de exigir responsabilidad penal a las personas jurídicas aun cuando no se pudiera individualizar a la persona (física) responsable, la intransmisibilidad de las circunstancias modificativas de la responsabilidad criminal de la persona física a la persona jurídica y la modulación de la pena de multa entre personas físicas y jurídicas. Lo que se contiene en el nuevo artículo 3I.ter es, en definitiva, la disgregación de la responsabilidad entre la persona física y la jurídica. Sin embargo, más allá de una reordenación sistemática, la reforma no plantea modificaciones en la redacción de este precepto.

${ }^{3}$ En lo que respecta al catálogo de sanciones previstas para las personas jurídicas, el proyecto de reforma no prevé ninguna modificación para el artículo 33.7 CP. Así es que se mantiene la enumeración taxativa original, que contiene un conjunto de penas, todas ellas con la consideración de graves, entre las que destaca la multa como consecuencia más común para la responsabilidad criminal de las personas jurídicas.

${ }^{4}$ Lo que se viene a justificar, fundamentalmente, en «lo anómalo de que el Estado ejerza la potestad punitiva sobre sí mismo o sobre los organismos mediante los cuales ejerce otras potestades» (MUÑOZ CONDE, F. y GARCÍA ARÁN, M., Derecho penal Parte general, Valencia, Tirant lo Blanch, 20IO, pág. 629).

5 La posibilidad de exigir responsabilidad criminal a los partidos políticos y a los sindicatos era algo mayoritariamente reclamado por la doctrina (v.g. MORALES PRATS, F., «La responsabilidad penal de las personas jurídicas, artículos 3i bis, 31.2, 33.7, 66 bis, I29, I30.2 CP», en QUINTERO OLIVARES, G. (dir.), La Reforma Penal de 2010: análisis y comentarios, Cizur Menor, Aranzadi, 20Io, pág. 66; DÍEZ RIPOLLÉS, J.L., «La responsabilidad penal de las personas jurídicas. Regulación española», en InDret, $n^{\circ} 1$, 2012, pág. II; ORTS BERENGER, E. y GONZÁLEZ CUSSAC, J.L., Compendio de Derecho Penal. Parte General, Valencia, Tirant lo Blanch, 20I0, pág. 239).
} 
El proyecto de Ley Orgánica de reforma del Código penal mantiene la redacción dada por la $\mathrm{LO}$ 7/20I2, recogiéndola en un nuevo artículo 31.quinquies. Pero además introduce un apartado segundo en este precepto con un contenido totalmente novedoso:

«En el caso de las Sociedades mercantiles públicas que ejecuten políticas públicas o presten servicios de interés económico general, solamente les podrán ser impuestas las penas previstas en las letras a) y g) del número 7 del artículo 33. Esta limitación no será aplicable cuando el Juez o Tribunal aprecie que se trata de una forma jurídica creada por sus promotores, fundadores, administradores o representantes con el propósito de eludir una eventual responsabilidad penal».

A través de esta modificación, se prevé que, junto a los sindicatos y los partidos políticos, también las empresas o sociedades mercantiles de carácter público puedan ser responsables penalmente. Entiéndase por tales sociedades aquéllas en las que la participación pública en su capital social sea superior al cincuenta por ciento, de acuerdo con lo previsto para las sociedades mercantiles estatales en la Ley de Patrimonio de las Administraciones públicas (art. I66.I.c LPAAPP) ${ }^{6}$. La responsabilidad, sin embargo, no será total, puesto que se limita (salvo que la forma jurídica haya sido creada para eludir la responsabilidad penal individual) a las penas de multa e intervención para salvaguardar los derechos de los trabajadores o acreedores. Lo cierto es que la inclusión de las sociedades mercantiles públicas en el régimen general de responsabilidad es positiva, y había sido demandada en términos generales por la doctrina, puesto que como ha afirmado QUINTERO OLIVARES, «genera una de las más clamorosas puertas abiertas a la corrupción y a la impunidad, sin entrar en la inaceptable desigualdad de trato respecto de las Sociedades mercantiles privadas» ${ }^{7}$.

\section{La «doble vía» de responsabilidad}

Desde la introducción en nuestro Derecho del modelo societas delinquere postest por la LO 5/20IO, nuestro sistema de responsabilidad de las personas jurídicas se ha basado siempre en una «doble vía» de atribución de responsabilidad a las personas jurídicas, en función de si el delito es cometido por representantes de la persona jurídica o por otras personas con la aquiescencia o pasividad de estos representantes (la llamada «actuación directa» y «actuación descontrolada» ${ }^{8}$ ). Una «doble vía» que, como señala FEIJOO SÁNCHEZ, sirve para generar la responsabilidad penal, pero no para «fundamentarla» ${ }^{9} \mathrm{y}$ que además depende siempre de las acciones u omisiones de los representantes o administradores de la persona jurídica.

Este sistema se mantiene, con ligeras modificaciones que no alteran el fundamento del sistema, en el proyecto de reforma; de manera que el artículo 3r.bis.I CP sigue

\footnotetext{
${ }^{6}$ Aunque también se exigirán requisitos adicionales para su caracterización: que ejecuten políticas públicas o presten servicios de interés económico general, como señala la Circular 1/2011 de la Fiscalía General del Estado (págs. 2I y 22).

${ }^{7}$ QUINTERO OLIVARES, G., «La responsabilidad penal de los partidos como personas jurídicas», en Actualidad Jurídica Aranzadi, versión electrónica, no 859, 2013, passim. 683.

${ }^{8}$ QUINTERO OlivareS, G., Parte General del Derecho Penal, Cizur Menor, Thomson Aranzadi, 2oio, pág.

9 FEIJOO SÁNCHEZ, B., «La responsabilidad penal de las personas jurídicas», en DÍAZ-MAROTO Y VILLAREJO, J. (dir.), Estudios sobre las reformas del Código Penal, Cizur Menor, 20II, Aranzadi, págs. 99 y Ioo.
} 
distinguiendo ambas vías, si cabe con mayor claridad conceptual, al diferenciar dos letras en la nueva redacción del precepto, que se expresa como sigue:

«En los supuestos previstos en este Código, las personas jurídicas serán penalmente responsables:

a) De los delitos cometidos en nombre o por cuenta de las mismas, y en su beneficio directo o indirecto, por sus representantes legales o por aquellos que actuando individualmente o como integrantes de un órgano de la persona jurídica, están autorizados para tomar decisiones en nombre de la persona jurídica u ostentan facultades de organización y control dentro de la misma.

b) De los delitos cometidos, en el ejercicio de actividades sociales y por cuenta y en beneficio directo o indirecto de las mismas, por quienes, estando sometidos a la autoridad de las personas físicas mencionadas en el párrafo anterior, han podido realizar los hechos por haberse incumplido por aquéllos los deberes de supervisión, vigilancia y control de su actividad atendidas las concretas circunstancias del caso».

Respecto de la primera vía (apartado a), se observa que se siguen manteniendo los tres elementos que configuraban esta vía de atribución de responsabilidad ${ }^{\text {10 }}$. En primer lugar, que los delitos se cometan «en nombre o por cuenta» de la persona jurídica correspondiente, lo que llevaría a excluir la responsabilidad de las sociedades en los casos en los que las actuaciones de las personas físicas se realizan en un ámbito privado o ajeno a la persona jurídica. En segundo lugar, es preciso que tales actuaciones se realicen en «beneficio directo o indirecto» de la persona jurídica, expresión que sustituye, acertadamente por su mayor nitidez, a la expresión anterior «en su provecho». En tercer lugar, las personas físicas que realizan la acción u omisión material deben ser los representantes o administradores tanto de derecho como de hecho. A mayor precisión, en este último caso el proyecto de reforma incluye entre los administradores «de hecho» a cualesquiera personas que estén autorizadas para tomar decisiones en nombre de la persona jurídica o que ostenten facultades de organización y control sobre ella.

La segunda vía (apartado b) también se mantiene, en esencia, tal como fue recogida en la LO 5/20IO. Ésta orbita sobre tres elementos similares a los anteriores: que los delitos se cometan «en el ejercicio de actividades sociales y por cuenta» de la persona jurídica correspondiente, que tales actuaciones se realicen en «beneficio directo o indirecto» de la persona jurídica y que los delitos sean cometidos por determinadas personas físicas: aquéllas que están sometidas a la autoridad de los representantes o administradores de derecho o de hecho de la primera vía. Por lo demás, continúa sin explicitarse qué personas físicas pueden cometer estos delitos, que habrá que reconducir, fundamentalmente aunque no en exclusiva, a los trabajadores o empleados de la persona jurídica, esto es, a aquellas personas físicas que pueden participar en el ejercicio de las actividades sociales de la persona jurídica y no se hallan incluidas en el nuevo artículo 3r.bis.I.a. Pero lo verdaderamente relevante no es la comisión de delitos por los subordinados, sino que los administradores o representantes incumplan sus deberes de supervisión, vigilancia y control respecto de aquéllos. Por ese motivo, esta vía de responsabilidad sigue manteniendo una redacción que nos recuerda a los delitos de comisión por omisión, al reproche in vigilando, que hace recaer siempre la responsabilidad criminal de las personas jurídicas sobre las actuaciones de los representantes o administradores de la entidad, a pesar de que

${ }^{\text {Io }}$ Tal y como indicábamos en: DÍAZ GÓMEZ, A., «El modelo de responsabilidad criminal de las personas jurídicas tras la LO 5/20I0», en Revista Electrónica de Ciencia Penal y Criminología, n I8, 20II, págs. 3 a 6. 
«aparentemente» la segunda vía recaiga sobre la comisión de delitos de los trabajadores $u$ otras personas.

\section{El nuevo delito de incumplimiento del deber de vigilancia o control en personas jurídicas y empresas: su incidencia en el sistema de atribución de responsabilidad a las personas jurídicas}

Continuando con la exposición antecedente, debe quedar claro que, en todo caso, de acuerdo con la segunda vía, la transferencia de responsabilidad a la persona jurídica por los delitos de los subordinados exige una acción u omisión previa de los administradores. Una conducta consistente en el incumplimiento de los deberes de supervisión, vigilancia y control, que posibilite la comisión de delitos por los trabajadores o subordinados. Lo cual, como ha venido interpretándose, no implica la existencia de un delito, ni siquiera de una conducta culpable, imputable a esos gestores (representantes legales o de hecho, en los términos mencionados) ${ }^{\mathrm{II}}$.

Sin embargo, la proyectada reforma pretende introducir una nueva sección cuarta bis dentro del capítulo XI del título XIII del libro II del Código Penal, con la rúbrica «Del incumplimiento del deber de vigilancia o control en personas jurídicas y empresas». Dentro de esta nueva sección se incluye un nuevo artículo 286.seis con el siguiente contenido:

«Será castigado con pena de prisión de tres meses a un año o multa de doce a veinticuatro meses, e inhabilitación especial para el ejercicio de la industria o comercio por tiempo de seis meses a dos años en todo caso, el representante legal o administrador de hecho o de derecho de cualquier persona jurídica o empresa, organización o entidad que carezca de personalidad jurídica, que omita la adopción de las medidas de vigilancia o control que resultan exigibles para evitar la infracción de deberes o conductas peligrosas tipificadas como delito, cuando se dé inicio a la ejecución de una de esas conductas ilícitas que habría sido evitada o, al menos, seriamente dificultada, si se hubiera empleado la diligencia debida.

Dentro de estas medidas de vigilancia y control se incluye la contratación, selección cuidadosa y responsable, y vigilancia del personal de inspección y control y, en general, las expresadas en los apartados 2 у 3 del artículo $3 \mathrm{I}$ bis.

2. Si el delito hubiera sido cometido por imprudencia se impondrá la pena de multa de tres a seis meses.

3. No podrá imponerse una pena más grave que la prevista para el delito que debió haber sido impedido u obstaculizado por las medidas de vigilancia y control omitidas»

A la luz de este nuevo precepto, podríamos preguntarnos si esta disposición que aparentemente se refiere exclusivamente a la responsabilidad criminal de la persona física (representante legal o administrador de hecho) puede afectar a la atribución de responsabilidad de la persona jurídica. Lo cierto es que la redacción del artículo 286.seis es criticable, porque al introducir la responsabilidad penal individual de los administradores, personas físicas, enreda el sistema de atribución de responsabilidad criminal de la persona

"FEIJOO SÁNCHEZ, B., «La responsabilidad penal de las personas jurídicas», cit., pág. IO4; DÍEZ RIPOLLÉS, J.L., Derecho Penal Español. Parte General en esquemas, Valencia, Tirant lo Blanch, 20II, págs. 250 y 25I; o Circular I/20II de la Fiscalía General del Estado, pág. 47, por ejemplo. Analizando la posible responsabilidad criminal de los administradores en la responsabilidad de la persona jurídica generada a través de la segunda vía vid. DOPICO GÓMEZ-ALLER, J., «Presupuestos básicos de la responsabilidad penal del compliance officer y otros garantes en la empresa», en Actualidad jurídica Aranzadi, n 843, 20I2, passim. 
jurídica, posibilitando que la responsabilidad de la persona jurídica se produzca, simultáneamente, por la primera y la segunda vía de atribución.

Parece claro que a través del nuevo 286.seis no se puede inferir la introducción de la necesidad de interpretar que el incumplimiento de los deberes de supervisión, vigilancia y control de la segunda vía requiera la comisión de este delito específico por los administradores, puesto que de haberse querido que así fuera se hubiera recogido expresamente. Sin embargo, no cabe duda que el proyectado artículo 286.seis guarda una relación muy estrecha con la atribución de responsabilidad a la persona jurídica a través de esta segunda vía. Así, aun entendiendo que este delito debe reservarse para los casos más graves, como ataque frontal al deber de objetivo cuidado, no cabe duda de que será un buen tertium comparationis entre la conducta de los representantes y el nivel de incumplimiento de sus deberes de acuerdo con la segunda vía; de modo que, si existe responsabilidad de los administradores conforme al artículo 286.seis, muy probablemente concurrirán los requisitos necesarios de la segunda vía de acuerdo con el artículo 3ı.bis.r.b proyectado.

Obviamente, esto ocurrirá siempre que no se cumplan a su vez las exigencias de la primera de las vías: que los representantes actúen en beneficio directo o indirecto de la persona jurídica y por su cuenta o en su nombre. Puesto que si se cumplen, el artículo 286.seis deberá caer inmediatamente dentro de la primera de las vías de atribución de responsabilidad de la persona jurídica, al tratarse de un delito cometido por los representantes o administradores de hecho o de derecho incluido en el numerus clausus al que nos referimos en el siguiente apartado (art. 288.2 en su redacción prevista).

\section{Los delitos susceptibles de comisión por las personas jurídicas}

Tras la LO 5/20io se introduce en el Código Penal un catálogo de delitos de los que pueden ser responsables las personas jurídicas, optándose por un sistema tasado numerus clausus en la parte especial, al hilo de cada uno de los tipos delictivos. Así, los delitos originalmente elegidos fueron los siguientes: tráfico ilegal de órganos (art. 156.bis.3 CP), trata de seres humanos (art. I77.bis.7 CP), delitos relativos a la prostitución y la corrupción de menores (art. I89.bis), delito de descubrimiento y revelación de secretos (art. I97.8 CP), delito de estafa (art. 251.bis CP), insolvencias punibles (art. 26r.bis), daños informáticos (art. 264.4 CP), delitos relativos a la propiedad intelectual e industrial, al mercado y a los consumidores (art. $288 \mathrm{CP}$ ), blanqueo de capitales (art. $302.2 \mathrm{CP}$ ), delitos contra la Hacienda Pública y la Seguridad Social (art. 3Io.bis CP), delitos contra los derechos de los ciudadanos extranjeros (art. 318.bis. 4.3. ${ }^{\circ} \mathrm{CP}$ ), delitos contra la ordenación del territorio (art. 3I9.4 CP), delitos contra los recursos naturales y el medio ambiente (arts. 327 y $328.6 \mathrm{CP}$ ), exposición a radiaciones ionizantes (art. $343.3 \mathrm{CP}$ ), delitos de riesgo provocados por explosivos y otros agentes (art. $348.3 \mathrm{CP}$ ), delitos relativos a drogas tóxicas, estupefacientes o sustancias psicotrópicas (art. 369 .bis.3. ${ }^{\circ} \mathrm{CP}$ ), delitos de falsificación de tarjetas de crédito y débito y cheques de viaje (art. 399.bis.I.3. ${ }^{\circ} \mathrm{CP}$ ), cohecho (art. $427.2 \mathrm{CP}$ ), tráfico de influencias (art. 430.3. ${ }^{\circ} \mathrm{CP}$ ), corrupción de funcionario público extranjero (art. 445.2 CP), delitos relacionados con las organizaciones y grupos criminales (art. 570.quáter.I CP) y delito de financiación del terrorismo (art. 576 bis.3 CP).

La LO 7/20I2 no ha modificado el catálogo de delitos de los que puede responsabilizarse a una persona jurídica, más allá de realizar alguna pequeña 
modificación ${ }^{\text {r2}}$. Por su parte, la proyectada reforma del Código Penal que estamos analizando no supone un gran cambio en este sentido. La reforma modifica algunos preceptos, como el artículo 288, para agravar la pena de multa por algunos delitos previstos en los artículos 277 y siguientes, e introduce el artículo 427.bis, con una redacción idéntica a la que se previó en el 427.2 CP, respecto de la responsabilidad de las personas jurídicas en el delito de cohecho. Además introduce la responsabilidad de las personas jurídicas en los nuevos delitos llamados de «frustración de la ejecución» (art. 258.ter), así como en los delitos de discriminación (art. 510.ter).

Los delitos recogidos en este numerus clausus guardan sin duda relación con el ámbito, esencialmente de tráfico económico o empresarial, en el que suelen desenvolverse las personas jurídicas. Sin embargo, si se examinan con más detalle los delitos escogidos por el legislador, no se comprende por qué se han seleccionado estos delitos y no otros que también se encuentran en la órbita de las personas jurídicas, lo cual genera sin duda incomprensión. Esto resulta especialmente estridente en algunos delitos, como en los llamados fraudes alimenticios o relativos a los medicamentos (arts. 359 a $365 \mathrm{CP}$ ) o los delitos societarios (arts. 290 a 297) ${ }^{13}$. Aún más en los delitos contra los derechos de los trabajadores (arts. 3I6 y 3I7), donde se asume que las personas jurídicas deben ejercer un importante papel en la prevención de riesgos laborales y se recoge la posibilidad de aplicar algunas de las medidas del artículo I29 CP. Así pues, el proyecto de reforma no prevé ninguna modificación de calado en este numerus clausus (más allá de los nuevos delitos de «frustración de la ejecución» y de discriminación), lo que nos lleva a pensar que la ausencia de alguno de estos delitos en la reforma de la LO 5/2010 no se debió a un error o un olvido, como podía imaginarse y aventuraban algunos autores ${ }^{\mathrm{I}}$. A la vista del proyecto, se pierde nuevamente la oportunidad de incorporar un catálogo de delitos más coherente y que responda a la realidad cotidiana del actuar de las personas jurídicas, pues se mantiene esencialmente la selección aparentemente azarosa efectuada por la LO 5/20Io.

${ }^{12}$ La LO 7/20I2 modifica el artículo 310.bis CP, que establece la responsabilidad criminal de las personas jurídicas en los delitos contra la Hacienda Pública y contra la Seguridad Social, para incluir la posibilidad de imponer a la persona jurídica la pérdida de la posibilidad de obtener subvenciones o ayudas públicas, del derecho a gozar de los beneficios o incentivos fiscales o de la Seguridad Social o la prohibición para contratar con las Administraciones Públicas. Además atenúa la responsabilidad en estos delitos, al establecer una nueva escala en relación con la pena de multa cuando el delito cometido por la persona física tenga prevista una pena de prisión de más de cinco años.

${ }^{13}$ Así Circular 1/2011 de la Fiscalía General del Estado, págs. 58 y 6o. En general, la doctrina configura un catálogo de delitos mucho más amplio, respecto de los cuales hubiera sido recomendable (y lógico) incluir la responsabilidad penal de las personas jurídicas; no sólo fraudes alimenticios y relativos a los medicamentos o delitos societarios, sino también: relativos a la manipulación genética, alteración de precios en concursos y subastas, contra los derechos de los trabajadores, falsificación de moneda, asociación ilícita, corrupción entre particulares, de riesgo provocados por explosivos, etc. (vid. v.g. RODRÍGUEZ GARCÍA, N., «Análisis de la regulación legal de la responsabilidad penal de las personas jurídicas en España», en NEIRA PENA, A. (coord.), Los retos del Poder Judicial ante la sociedad globalizada, A Coruña, Universidade da Coruña, 20II, pág. 208, notas al pie $\mathrm{n}^{\circ} 36$ y 37; GALLEGO DÍAZ, M., «Las penas aplicables a las personas jurídicas en el Código Penal español», en Revista Penal, nº 3I, 20I3, pág. 86; DÍEZ RIPOLLÉS, J.L., Derecho Penal Español. Parte General en esquemas, cit., pág. 244). Incluso algún autor considera que sería coherente y operativo admitir otros como homicidio y lesiones graves (GÓMEZ TOMILLO, M., Introducción a la responsabilidad penal de las personas jurídicas en el sistema español, Valladolid, Lex Nova, 20ı0, pág. I9).

${ }^{14}$ V.g. MUÑOZ CONDE, F., Derecho Penal. Parte especial, Valencia, Tirant lo Blanch, 20I3, pág. 333; ZUGALDÍA ESPINAR, J.M., «Societas delinquere potest: análisis de la reforma operada en el Código Penal español por la LO 5/2010, de 22 de junio», en La ley penal, versión electrónica, nº 76, 2010, pág. 9. 


\section{Cancelación de penas y antecedentes}

El proyecto de reforma del Código Penal también incluye como novedad la introducción de previsiones específicas sobre la cancelación de los antecedentes delictivos de las personas jurídicas, inexistentes en el modelo introducido por la LO 5/20IO. Recogería así un reformado artículo 136.4 que:

«Las penas impuestas a las personas jurídicas y las consecuencias accesorias del artículo I29 se cancelarán en el plazo que corresponda, de acuerdo con la regla prevista en el apartado primero de este artículo, salvo que se hubiese acordado la disolución o la prohibición definitiva de actividades. En estos casos, se cancelarán las anotaciones transcurridos 50 años computados desde el día siguiente a la firmeza de la sentencia».

El precepto se completa con la previsión de un nuevo artículo i36.bis, que en su apartado tercero se refiere a los plazos para cursar la correspondiente baja en el Registro Central de Penados en el caso de las personas jurídicas:

«Las penas impuestas a las personas jurídicas y las consecuencias accesorias del artículo i29 se darán de baja por el Registro Central de Penados cuando hayan transcurrido roo años desde el día siguiente a la fecha de la sentencia firme, siempre que no se haya anotado ningún nuevo procedimiento sobre la misma entidad. En este último caso, el plazo comenzará a computarse de nuevo desde el día siguiente a la fecha de la sentencia firme correspondiente a la última anotación».

Ambos preceptos vienen, por tanto, a establecer el régimen de cancelación y baja de los antecedentes delictivos en el caso de las penas impuestas a las personas jurídicas. La cancelación de las anotaciones de las penas, puesto que tienen la consideración de graves (ex. art. 33.7 CP), se hará, de conformidad con el proyecto de reforma, en el plazo de diez años desde el día siguiente a la firmeza de la sentencia; excepto en el caso de la pena de disolución de la persona jurídica o de prohibición definitiva de realizar actividades, que se hará en el plazo de cincuenta años. Sin embargo, se darán de baja en el Registro Central de Penados cuando hayan transcurrido cien años desde el día siguiente a la fecha de sentencia firme. Respecto a la introducción de estas modificaciones, más allá de la extrañeza que supone la necesidad de que transcurran cincuenta años para cancelar las anotaciones una vez extinta (desaparecida) la persona jurídica, como ha puesto de manifiesto algún autor que ya se ha pronunciado al respecto ${ }^{15}$, debería analizarse si cien años no es también un tiempo excesivamente dilatado y estigmatizante, incluso aunque se trate de una persona jurídica, para dar de baja en el Registro Central de Penados las correspondientes anotaciones de las penas ${ }^{16}$. En este sentido, la reputación empresarial quedaría seriamente afectada, innecesariamente, por un tiempo excesivamente prolongado, dificultando la reinserción social, si es que puede predicarse tal cosa respecto de las personas jurídicas, o su reconducción conforme a Derecho.

\footnotetext{
${ }^{15}$ MANZANARES SAMANIEGO, J.L., «Comentarios a la reforma de la parte general del Código Penal conforme al nuevo anteproyecto de Ley Orgánica (y IV)», en Diario La Ley, versión electrónica, n 8003, 20I3, págs. II y I2. Más extraño resulta si se tiene en cuenta que la pena de disolución equivale llanamente a la muerte de la persona jurídica ( $c f r$. v.g. DÍEZ RIPOLLÉS, J.L., «Las penas de las personas jurídicas, y su determinación legal y judicial: regulación española», en FERNÁNDEZ TERUELO, J.G. (dir.), Estudios penales en homenaje al profesor Rodrigo Fabio, Oviedo, Constitutio Criminalis Carolina, 2013, pág. I98), y el artículo I36.bis que introduce la reforma sienta explícitamente que «el Registro Central de Penados procederá además a dar de baja las anotaciones correspondientes a las personas fallecidas».

${ }^{16}$ Como viene a decir el Consejo General del Poder Judicial; cfr. su Informe al Anteproyecto de Ley Orgánica por la que se modifica la Ley Orgánica 10/1995, de 23 de noviembre, del Código Penal (2013), págs. I49 y I50.
} 


\section{Circunstancias modificativas de la responsabilidad}

Respecto a las circunstancias modificativas de la responsabilidad criminal, el único cambio previsto en el proyecto de reforma respecto a la regulación recogida en el artículo 3r.bis.4 CP, es la colocación del contenido inalterado de este precepto en un nuevo artículo 3I.quáter. Así pues, se continúan recogiendo cuatro circunstancias de atenuación ex post facto en los mismos términos que fueron introducidos por la LO 5/2010, sin introducirse ninguna otra circunstancias modificativa de la responsabilidad para las personas jurídicas. Se trataría de atenuantes que no pueden situarse dentro del elemento de la culpabilidad en la teoría jurídica del delito, como ha señalado la doctrina ${ }^{\mathrm{r}}$, pues obedecen a una menor necesidad de la pena por razones prácticas en atención a la colaboración entre el Estado y las personas jurídicas en la línea del fenómeno de la autorregulación empresarial ${ }^{18}$.

Sin embargo, a pesar de que un nuevo artículo 31.quáter quedaría configurado en los mismos términos que el artículo 31.bis.4 introducido por la LO 5/2010, circunscribiendo rigurosamente las atenuantes a las expresamente mencionadas («sólo podrán considerarse circunstancias atenuantes [...] las siguientes actividades»), se introducen dos novedades que vienen a atenuar o limitar la cuantía de la pena.

En primer lugar, en el nuevo apartado 2 in fine del artículo 31.bis se prevé introducir la siguiente cláusula:

«En los casos en los que las anteriores circunstancias solamente puedan ser objeto de acreditación parcial, esta circunstancia será valorada a los efectos de atenuación de la pena».

Se trata, pues, de la posibilidad de atenuar la pena en los supuestos en que anteriormente a la comisión del delito que genera responsabilidad penal para la persona jurídica, ya sea por la primera o la segunda vía, existiera un modelo de prevención de delitos que no reúna todos los requisitos o condiciones para eximir de responsabilidad. Respecto a los modelos de prevención, nos referiremos a ellos en el siguiente apartado. En cuanto a esta circunstancia de atenuación, debe valorarse positivamente que se pretenda premiar a aquellas personas jurídicas que implementan un programa específico de prevención de delitos, demostrando estar concienciadas con el cumplimiento de la legalidad penal, aunque no se trate de un modelo de prevención que reúna todos los requisitos. Por el contrario, en nuestra opinión debería incluirse esta circunstancia junto con las demás circunstancias atenuantes del nuevo artículo 3I.quáter, para que pudiera reconducirse sin duda alguna, en cuanto a la aplicación de la pena, al artículo 66 CP.

En segundo lugar, dentro de las reglas generales para la aplicación de las penas, se introduce un nuevo párrafo en el artículo 66.bis.2 ${ }^{\mathrm{a}}$, con el siguiente contenido:

«Cuando la responsabilidad de la persona jurídica, en los casos previstos en la letra b) de apartado I del artículo 3i bis, derive de un incumplimiento de los deberes de supervisión, vigilancia y control que no tenga carácter grave, estas penas tendrán en todo caso una duración máxima de dos años».

${ }^{17}$ DÍEZ RIPOLLÉS, J.L., «La responsabilidad penal de las personas jurídicas. Regulación española», cit., pág. 25; MUÑOZ CONDE, F. y GARCÍA ARÁN, M., Derecho penal Parte general, cit., pág. 632; FEIJOO SÁNCHEZ, B., «La responsabilidad penal de las personas jurídicas», cit., pág. I29.

${ }^{18}$ Así, vid. GÓMEZ-JARA DÍEZ, C., «Aspectos sustantivos relativos a la responsabilidad penal de las personas jurídicas», en BANACLOCHE PALAO, J., ZARZALEJOS NIETO, J. y GÓMEZ-JARA DÍEZ, C., Responsabilidad penal de las personas jurídicas: aspectos sustantivos y procesales, Madrid, La Ley, 20II, pág. 90. 
Esta modificación viene a introducir una nueva circunstancia para graduar e imponer las sanciones previstas en las letras c) a g) del artículo 33.7 CP. De esta manera, cuando la responsabilidad de la persona jurídica se genere a través de la segunda vía, si los representantes o administradores de derecho o de hecho de la persona jurídica no incumplen los deberes que posibilitan la comisión de delitos de forma «grave», la duración de las penas (suspensión de actividades, clausura de locales, prohibición de realizar actividades, inhabilitación para obtener subvenciones, ayudas, beneficios y contrataciones e intervención judicial) no van a poder exceder de dos años. Por otro lado, la referencia a que el incumplimiento de los deberes «no tenga carácter grave», impediría aplicar esta previsión a aquellos casos en que se sancionase además por el delito del nuevo artículo 286.seis.

Obviamente, no podemos considerar esta nueva previsión como una circunstancia atenuante, pues se encuentra fuera de la enumeración taxativa de atenuantes válidas para las personas jurídicas y no se rige por tanto por el artículo 66 CP. Sin embargo, sí debe valorarse positivamente $\mathrm{su}$ introducción, como medida que, al contrario que las circunstancias del artículo 3r.bis.4 CP, juega ex ante facto, que no se refiere tanto a la actuación sociedad como a las personas físicas responsables de los deberes del control, que afectaría a la categoría de la culpabilidad, y que va a servir no para atenuar la responsabilidad, pero sí para limitarla.

\section{Un nuevo impulso a la autorregulación: la importancia de los modelos de prevención empresarial como exención de responsabilidad de las personas jurídicas}

Sin duda la novedad más importante y más trascendente a efectos prácticos que plantea el proyecto de reforma del Código Penal en lo que atañe a la responsabilidad penal de las personas jurídicas es la modificación del artículo 3r.bis, para recoger (además de la doble vía de atribución de responsabilidad que ya se contenía de manera sustancialmente similar en la LO 5/20I0) un sistema de exención de responsabilidad criminal basado en la adopción eficaz ex ante facto de programas que eviten la comisión de hechos delictivos.

Conforme al sistema establecido por la LO 5/20IO, la incidencia de la autorregulación se agota en el artículo 3r.bis.4.d CP, que establece como circunstancia atenuante «haber establecido, antes del comienzo del juicio oral, medidas eficaces para prevenir y descubrir los delitos que en el futuro pudieran cometerse con los medios o bajo la cobertura de la persona jurídica». Sorprendentemente, la adopción ex ante de alguna de estas medidas no excluye la responsabilidad penal de las personas jurídicas, algo que acertadamente trata de solventar la reforma que analizamos. Con la proyectada reforma del Código Penal, la autorregulación asume expresamente una importancia nunca antes vista en la norma penal.

La autorregulación, desde el punto de vista de la criminalidad de las personas jurídicas, implica la adopción por parte de las mismas de medidas organizativas encaminadas a la prevención de ilícitos penales en su seno. En último lugar, su fundamento es la motivación a las empresas para que incrementen su nivel de gestión, organización y control para evitar la comisión de hechos delictivos ${ }^{\text {I9 }}$. En este sentido, los

${ }^{19}$ NIETO MARTÍN, A., La responsabilidad penal de las personas jurídicas: un modelo legislativo, Madrid, Iustel, 2008, pág. 2I5. 
planes de autoorganización y autorregulación se vuelcan en los llamados programas de cumplimiento («compliance programs» en su término tradicional norteamericano) o modelos de organización o prevención o códigos de conducta corporativa, entre otras denominaciones. En la práctica, en nuestro propio país la existencia de tales programas o modelos se ha venido plasmando en instrumentos muy variados y de diversa terminología: códigos de conducta, de buen gobierno, de buenas prácticas, técnicos o éticos, etc. ${ }^{20}$. Todos ellos tienen en común la voluntad de interiorizar un programa de cumplimiento del Derecho y respeto a la legalidad.

Pero los códigos de conducta corporativos a los que nos estamos refiriendo son impulsados principalmente desde la perspectiva privada (no estatal). Tales programas se asocian con la creciente tendencia empresarial a asumir la responsabilidad social; de modo que muchas personas jurídicas introducen, motu proprio, directrices éticas de comportamiento para la prevención no sólo de la delincuencia, sino de otros elementos disfuncionales para las sociedades. Ejemplos de ello son las propuestas que despuntan en los últimos años sobre la creación de «Códigos de Buen Gobierno» sobre las sociedades cotizadas, recogiendo todo tipo de recomendaciones, de aceptación voluntaria y sin eficacia jurídica vinculante, que oscilan sobre la idea de la «Corporate Governance» (buen gobierno corporativo $)^{21}$. De este modo, los códigos de conducta, anclados muchas veces sobre el difuso concepto de «ética empresarial», se esparcen sobre los ámbitos más diversos y con eficacia y contenido no uniforme ${ }^{22}$.

Desde el estricto punto de vista de la responsabilidad penal de las personas jurídicas, lo cierto es que los postulados de la autorregulación empresarial han sido escasamente estudiados por nuestra doctrina criminalista, pues prácticamente sólo dos autores (ADÁN NIETO y GÓMEZ-JARA DÍEZ) han prestado atención a la cuestión. Sin embargo, el desconocimiento científico que puede existir en relación a la influencia de la autorregulación en la responsabilidad penal de las personas jurídicas no debe hacernos caer en el error de que es una institución nueva totalmente ajena a un ordenamiento jurídico como el español. Opuestamente, como indicaba ADÁN NIETO, «no supone importar un cuerpo legislativo extraño procedente de otra galaxia jurídica» ${ }^{23}$.

${ }^{20}$ NIETO MARTÍN, A., «Responsabilidad social, gobierno corporativo y autorregulación: sus influencias en el derecho penal de la empresa Política Criminal», en Revista Electrónica Semestral de Políticas Públicas en Materias Penales, $\mathrm{n}^{\circ}$ 5, 2008 , pág. 5 .

${ }^{21}$ Destacan el denominado «Código Olivencia» (donde se trata de redefinir el papel del Consejo de Administración como un instrumento de supervisión y control de la gestión de las empresa) y el «Informe Aldama» (que recoge una serie de recomendaciones para el fomento de la transparencia y la seguridad de los mercados, poniendo especial énfasis en el mantenimiento de una información transparente, correcta, equitativa, etc.). Ambos se fundirían en el llamado «Código Unificado de recomendaciones sobre Buen Gobierno de las Sociedades cotizadas». Vid. sucintamente BROSETA PONT, M. y MARTÍNEZ SANZ, F., Manual de Derecho mercantil, vol.I, Madrid, Tecnos, 2008, págs. 427 SS.

${ }^{22}$ RODOTÁ, S., «Códigos de conducta: entre el hard law y el soft law», en REAL PÉREZ, A. (coord.), Códigos de conducta y actividad económica, una perspectiva jurídica, Madrid, Marcial Pons, 20Io, págs. 23 ss. A propósito de esta obra, acerca de los códigos de conducta puede verse en profundidad: REAL PÉREZ, A. (coord.), Códigos de conducta y actividad económica, una perspectiva jurídica, Madrid, Marcial Pons, 2010.

${ }^{23}$ NIETO MARTÍN, A., La responsabilidad penal de las personas jurídicas: un modelo legislativo, cit., pág. 2I8. Al contrario, dirá el mismo autor, «se trata más bien de terminar de construir el edificio, una vez que tenemos ya preparados el subsuelo y los cimientos» (ibid.). El símil de la construcción permite gráficamente poner de relieve la idea de que la autorregulación para la prevención de delitos, basada en modelos organizativos o programas de cumplimiento, no es nada nuevo en el Derecho español, de modo que supuestos autorregulatorios que sean exigencia del legislador pueden verse, exempli gratia, en el marco de la lucha contra el blanqueo de capitales, riesgos laborales, medio ambiente o defensa de consumidores (ibid. págs. 2I6 y 2I7). 
Pero el peso que efectivamente juegue la autorregulación en nuestro sistema penal depende del modelo de imputación de las personas jurídicas que configure la norma. En este sentido, si entendemos que el legislador configuró un auténtico sistema de autorresponsabilidad penal y culpabilidad de las personas jurídicas, como señalaron algunos autores, la autorregulación será un elemento esencial sobre el cual poder determinar si se produce un defecto de organización que permita imputar la responsabilidad a la persona jurídica ${ }^{24}$. Sin embargo, incluso aunque creamos que de lege data no nos encontremos ante un verdadero modelo de culpabilidad, tampoco podría negarse la importancia de los modelos de autorregulación para determinar la responsabilidad penal. En un trabajo precedente indicamos que, a pesar de que en nuestra opinión el Legislador configuró un modelo mixto de imputación, la existencia de programas preventivos efectivos debía tener alguna incidencia sobre la responsabilidad criminal de la persona jurídica que los adoptara ${ }^{25}$.

En efecto, la lógica dice que si la existencia del programa preventivo posterior al ilícito puede atenuar la responsabilidad, uno anterior debería eximirla, e igualmente esta interpretación se acompaña mejor con el principio de culpabilidad y cumpliría mejor los fines preventivos de la pena. Pero a pesar de que una buena parte de la doctrina se manifestaba partidaria de no responsabilizar penalmente a la persona jurídica en estos $\operatorname{casos}^{26}$, lo cierto es que el tenor de la norma tal y como es configurada por la LO 5/2010 no permite llegar fácilmente a esta conclusión. La inaceptable paradoja es que, como indicaba FEIJOO SÁNCHEZ, de atender al tenor literal del texto legal, las personas jurídicas acabarían respondiendo penalmente aunque se comportaran correctamente, esto es, aunque fueran diligentes y hubieran implementado correctamente un programa de prevención de delitos; de modo que ello implicaría que «las personas jurídicas en realidad no pueden hacer nada contra la responsabilidad penal» ${ }^{27}$.

Afortunadamente, las incoherencias de esta situación buscan ser superadas por el proyecto de reforma, como decíamos, en una de sus más importantes novedades. La

\footnotetext{
${ }^{24}$ Efectivamente, en los modelos de autorresponsabilidad penal de las personas jurídicas la autorregulación tiene una gran importancia. Muy especialmente, los sistemas basados en la autoculpabilidad de la persona jurídica se orientan a estimular su fidelidad al Derecho a través de una autorregulación empresarial que en definitiva conlleva el establecimiento de una «cultura empresarial de cumplimiento con del Derecho» (GÓMEZJARA DÍEZ, C., «Autoorganización empresarial y autorresponsabilidad empresarial: Hacia una verdadera responsabilidad penal de las personas jurídicas», en Revista electrónica de ciencia penal y criminología, n ${ }^{\circ}$ 8, 2006, pág. 26). Desde esta perspectiva, adquiere gran relevancia el «defecto de organización» como elemento que permite afirmar que una persona jurídica es culpable conforme a Derecho. Así, la culpabilidad de la empresa por defecto de organización significa que no se han cumplido eficazmente las obligaciones de autorregulación que impone el Derecho, y donde no existan tales regulaciones, aquéllas que imponen los códigos éticos o de conducta (NIETO MARTÍN, A., La responsabilidad penal de las personas jurídicas: un modelo legislativo, cit., pág. 2I8).

${ }^{25}$ DÍAZ GÓMEZ, A., «El modelo de responsabilidad criminal de las personas jurídicas tras la LO 5/2010», cit., págs. 20 a 26.

${ }^{26}$ V. g. ZUGALDÍA ESPINAR, J.M., «Societas delinquere potest: análisis de la reforma operada en el Código Penal español por la LO 5/20IO, de 22 de junio», cit., pág. IO; BACIGALUPO ZAPATER, E., «Responsabilidad penal y administrativa de las personas jurídicas y programas de «compliance»: a propósito del Proyecto de reformas del Código Penal de 2009», en Diario La Ley, versión electrónica, $\mathrm{n}^{\circ}$ 7442, 20Io, pág. 8; ORTIZ DE URBINA GIMENO, I., «Responsabilidad penal de las personas jurídicas y programas de cumplimiento empresarial («compliance programs»)», en GOÑI SEIN, J.L. (dir.), Ética empresarial y códigos de conducta, Madrid, La Ley, 20II, pág. I30.

${ }^{27}$ FEIJOO SÁNCHEZ, B., «Autorregulación y Derecho Penal de la empresa: ¿una cuestión de responsabilidad individual?», en ARROYO JIMÉNEZ, L., y NIETO MARTÍN, A. (dirs.), Autorregulación $y$ Sanciones, Valladolid, Lex Nova, 2008, pág. 209.
} 
modificación del artículo 3r.bis CP que se prevé viene expresamente a establecer la exención de responsabilidad penal de la persona jurídica dando vía libre a la introducción de la autorregulación en el Código Penal, diferenciando una y otra vía de atribución de responsabilidad. Así, en el caso de que la responsabilidad de la persona jurídica se genere a través de la primera vía, establece el apartado segundo del artículo 3ı.bis que:

«Si el delito fuere cometido por las personas indicadas en la letra a) del apartado anterior, la persona jurídica quedará exenta de responsabilidad si se cumplen las siguientes condiciones:

I. $\left.{ }^{2}\right)$ el órgano de administración ha adoptado y ejecutado con eficacia, antes de la comisión del delito, modelos de organización y gestión que incluyen las medidas de vigilancia y control idóneas para prevenir delitos de la misma naturaleza;

2. $\left.{ }^{a}\right)$ la supervisión del funcionamiento y del cumplimiento del modelo de prevención implantado ha sido confiado a un órgano de la persona jurídica con poderes autónomos de iniciativa y de control;

$\left.3{ }^{2}\right)$ los autores individuales han cometido el delito eludiendo fraudulentamente los modelos de organización y de prevención, y;

4. $\left.{ }^{\circledR}\right)$ no se ha producido una omisión o un ejercicio insuficiente de sus funciones de supervisión, vigilancia y control por parte del órgano al que se refiere la letra b).

En los casos en los que las anteriores circunstancias solamente puedan ser objeto de acreditación parcial, esta circunstancia será valorada a los efectos de atenuación de la pena».

El apartado tercero establece una previsión específica para las personas jurídicas de pequeñas dimensiones ${ }^{28}$, donde la supervisión del funcionamiento y del cumplimiento del modelo de prevención puede realizarse directamente por el órgano de administración, no siendo necesaria la creación de un órgano específico con autonomía para la supervisión del modelo de organización; entendemos que en aras de que las exigencias de autorregulación no supongan cargas excesivas para las personas jurídicas de pequeñas dimensiones ${ }^{29}$.

«En las personas jurídicas de pequeñas dimensiones, las funciones de supervisión a que se refiere la condición 2. ${ }^{a}$ del apartado 2 podrán ser asumidas directamente por el órgano de administración. A estos efectos, son personas jurídicas de pequeñas dimensiones aquéllas que, según la legislación aplicable, estén autorizadas a presentar cuenta de pérdidas y ganancias abreviada»

Por último, en lo que respecta a la responsabilidad generada a través de la segunda vía, el apartado cuarto quedaría redactado de tal forma:

«Si el delito fuera cometido por las personas indicadas en la letra b) del apartado I, la persona jurídica quedará exenta de responsabilidad si, antes de la comisión del delito, ha adoptado y ejecutado eficazmente un modelo de organización y gestión que resulte adecuado para prevenir delitos de la naturaleza del que fue cometido.

En este caso resultará igualmente aplicable lo dispuesto en el párrafo segundo del número 2 de este artículo».

${ }^{28}$ Vid. arts. 258 y 536 del RDLeg. I/20IO.

${ }^{29}$ Indica GÓMEZ-JARA DÍEZ, que en las grandes organizaciones el programa de prevención deberá ser llevado a cabo por un departamento diferenciado de la organización, «mientras que en pequeñas empresas puede resultar lógico que las mismas personas que ejecuten las actividades empresariales habituales, supervisen igualmente el compliance» (GÓMEZ-JARA DÍEZ, C., «Aspectos sustantivos relativos a la responsabilidad penal de las personas jurídicas», cit, pág. 95). 
Se observa, pues, que las exigencias para eximir de responsabilidad penal a la persona jurídica son mayores en el caso de que los delitos sean cometidos por los administradores o representantes de hecho o de derecho de la primera vía que en el supuesto de que sean cometidos por los subordinados en la segunda vía. En el primer caso, se exige que concurran todas y cada una de las condiciones enumeradas: que exista efectivamente un modelo de prevención idóneo para evitar la comisión de delitos por los administradores, que su cumplimiento se confíe a un órgano autónomo en el interior de la persona jurídica (salvo en el caso de personas jurídicas de pequeñas dimensiones) y que el delito se cometa eludiendo el programa y sin que el órgano encargado del control haya omitido sus funciones de supervisión y vigilancia ${ }^{30}$. En el segundo caso, basta con que se haya adoptado y ejecutado eficazmente con carácter previo al delito un modelo de prevención. En el supuesto de que la responsabilidad de la persona jurídica se generase simultáneamente por ambas vías, parece que deberán cumplirse los requisitos de cada una de ellas, es decir, que se haya implementado eficazmente un modelo de prevención dirigido a evitar delitos tanto de los administradores como de los subordinados.

La existencia del modelo debe acreditarse en su integridad, de lo contrario no podrá servir para eximir la responsabilidad penal de la persona jurídica, sino, como mucho, como una causa de atenuación. Por lo demás, téngase en cuenta que a pesar de todas estas cautelas tomadas por los órganos encargados de la persona jurídica, el delito se acaba finalmente cometiendo, bien por los representantes, bien por los subordinados. Quiere decirse que la «eficacia» a la que hace referencia la reforma nunca puede medirse en términos de constatación de hechos delictivos, puesto que entonces no tendría razón de ser esta exención de responsabilidad criminal. Los programas de prevención deben valorarse, pues, con un criterio de idoneidad ex ante, sin exigir que sea imposible la comisión de hechos delictivos ${ }^{31}$.

Del mismo modo, cabría señalar que un código de conducta o programa de cumplimiento debe marcarse una serie de objetivos y prioridades, que variarán dependiendo de las peculiaridades del sector en el que nos encontremos. Por supuesto, en este sentido deberán tenerse en cuenta los delitos e infracciones que más afectan a la persona jurídica por el tipo de actividad que desarrolla ${ }^{32}$. No debe olvidarse asimismo la importancia que los mecanismos de vigilancia y la sanción tienen respecto de cualquier programa de prevención. Los modelos de prevención deberán, pues, entenderse integrados en el sistema de control de la persona jurídica, de manera que los órganos de dirección de ésta se aseguren de que el modelo se cumple. Tal control, no obstante, puede ser tanto interno como externo a la entidad, a través de auditorías independientes o agentes del Estado $^{33}$. Como señala NIETO MARTÍN, la monitorización de los programas de cumplimiento hace surgir la idea de una policía de empresa y la aparición de los llamados

\footnotetext{
${ }^{30}$ Pese a su redacción, entendemos que la «letra b)» a la que se refiere el proyectado artículo $31 . b i s .4 \cdot{ }^{\text {a) }}$ es en realidad el apartado $2 .{ }^{a}$ ) del artículo 3r.bis.4.

${ }^{31}$ Así, GÓMEZ-JARA DÍEZ, C., «Aspectos sustantivos relativos a la responsabilidad penal de las personas jurídicas», cit, pág. 95.

${ }^{32}$ NIETO MARTÍN, A., La responsabilidad penal de las personas jurídicas: un modelo legislativo, cit., pág. 24I SS.

${ }^{33}$ Ibid. págs. 248 a 263 .
} 
«gatekeepers» (guardianes), encargados de velar por el cumplimiento de la legalidad en la empresa y que responden penalmente por esta razón ${ }^{34}$.

Respecto de los requisitos que debiera reunir un buen modelo de organización, reproducimos la propuesta de GÓMEZ-JARA DÍEZ, que diferencia distintos ámbitos a la hora de analizar un programa de cumplimiento efectivo. Así por ejemplo, dicho programa debe reflejar los esfuerzos de la persona jurídica en promover una cultura de respeto a la legalidad, debe tener en cuenta factores como el tamaño de la organización o el tipo de actividad que desarrolla, debe cumplir con los estándares estatales o de la industria que rijan en el ámbito en que se desenvuelve o debe ser actualizado periódicamente ${ }^{35}$. También debe seguir siete pilares básicos, a saber: «I) Existencia de estándares y procedimientos relativos al Compliance -especialmente un código de conducta escrito-. 2) Supervisión de los esfuerzos de cumplimiento por parte del personal altamente cualificado. 3) No delegación de los poderes discrecionales de las autoridades administrativas en personal con posible tendencia delictiva. 4) Comunicación efectiva de los estándares y procedimiento contenidos en los códigos de conducta. 5) Reforzamiento mediante sistemas efectivos de control y auditoría. 6) Reforzamiento mediante procedimientos disciplinarios. 7) Adopción de medidas adecuadas tras la detección de la infracción ${ }^{36}$. Siguiendo la experiencia de Derecho comparado, otros autores en España se han manifestado en términos similares ${ }^{37}$.

El proyecto de reforma del Código penal ha tenido en cuenta todos estos elementos, recogiendo unos mínimos necesarios para que el modelo de organización y prevención permita eximir de responsabilidad a la persona jurídica. Se recogerían en el apartado quinto del reformado artículo 3r.bis como sigue:

«Los modelos de organización y gestión a que se refieren la condición I. ${ }^{a}$ del apartado 2 y el apartado anterior, deberán cumplir los siguientes requisitos:

I. Identificarán las actividades en cuyo ámbito puedan ser cometidos los delitos que deben ser prevenidos.

2. Establecerán los protocolos o procedimientos que concreten el proceso de formación de la voluntad de la persona jurídica, de adopción de decisiones y de ejecución de las mismas con relación a aquéllos.

3. Dispondrán de modelos de gestión de los recursos financieros adecuados para impedir la comisión de los delitos que deben ser prevenidos.

4. Impondrán la obligación de informar de posibles riesgos e incumplimientos al organismo encargado de vigilar el funcionamiento y observancia del modelo de prevención.

\footnotetext{
${ }^{34}$ NIETO MARTÍN, A., «Responsabilidad social, gobierno corporativo y autorregulación: sus influencias en el derecho penal de la empresa Política Criminal», cit., pág. I3.

${ }^{35}$ GÓMEZ-JARA DÍEZ, C., «Aspectos sustantivos relativos a la responsabilidad penal de las personas jurídicas», cit, págs. 94 ss.

${ }^{36}$ Ibid. pág. 94.

${ }^{37}$ V.g. ALONSO GALLO, J., «Los programas de cumplimiento», en DÍAZ-MAROTO Y VILLAREJO, J. (dir.), Estudios sobre las reformas del Código Penal, cit., págs. I66 ss.; ORTIZ DE URBINA GIMENO, I., «Responsabilidad penal de las personas jurídicas y programas de cumplimiento empresarial («compliance programs»)», cit., pág.I28; BACHMAIER WINTER, L., «Responsabilidad penal de las personas jurídicas: definición y elementos de un programa de compliance», en Diario La Ley, $\mathrm{n}^{\circ}$ 7938, 20I2, págs. 4 SS.; MAGRO SERVET, V., «Contenido necesario del plan de prevención jurídica de las empresas para evitar responsabilidades penales», en La Ley Penal, versión electrónica, nº 87, 20II, págs. 6 y 7.
} 
5. Establecerán un sistema disciplinario que sancione adecuadamente el incumplimiento de las medidas que establezca el modelo.

El modelo contendrá las medidas que, de acuerdo con la naturaleza y el tamaño de la organización, así como el tipo de actividades que se llevan a cabo, garanticen el desarrollo de su actividad conforme a la Ley y permitan la detección rápida y prevención de situaciones de riesgo, y requerirá, en todo caso:

a) de una verificación periódica del mismo y de su eventual modificación cuando se pongan de manifiesto infracciones relevantes de sus disposiciones, o cuando se produzcan cambios en la organización, en la estructura de control o en la actividad desarrollada que los hagan necesarios; y

b) de un sistema disciplinario que sancione adecuadamente las infracciones de las medidas de control y organización establecidas en el modelo de prevención»

Queda por realizar una última consideración, relativa a la introducción de los modelos de prevención como circunstancias que permiten la exención de responsabilidad criminal de las personas jurídicas. De acuerdo con el texto del Proyecto de Ley, resulta evidente la enorme importancia que adquieren los sistemas de organización y prevención de delitos en el ámbito de las personas jurídicas, pues determinan en última instancia la existencia de responsabilidad penal. De esta manera, se introduciría en nuestro Código Penal un modelo de imputación de las personas jurídicas basado, ahora sí, en el «defecto de organización», entendido como la no implementación (o implementación inadecuada) de los modelos de prevención de delitos. Es cierto, sin embargo, que no se prescinde de la existencia de un «hecho de conexión», un delito imputable a una persona física que varía en función de la vía de atribución de responsabilidad en la que nos encontremos. Pero lo que no puede negarse es que se da un paso de gigante hacia un modelo de culpabilidad y responsabilidad autónoma de la persona jurídica, reforzando las posiciones de aquellos autores que afirmaban que ya con el sistema introducido por la LO 5/2010 existía tal modelo ${ }^{38}$. Así, a la disgregación de responsabilidades entre persona física y persona jurídica que ya se recogía en el Código Penal tras la LO 5/2010 (y que en el proyecto de reforma se contiene en el nuevo artículo 3 I.ter $)^{39}$, se le añade la posibilidad de que la persona jurídica atenúe o exima su responsabilidad, de manera autónoma, si ha adoptado y ejecutado adecuadamente determinados modelos y programas de prevención de delitos, circunstancias que no se dirigen sino a la propia persona jurídica y su culpabilidad. Por tanto, de modificarse el Código Penal en el sentido que hemos mencionado, el sistema de responsabilidad penal de las personas jurídicas caminaría desde un modelo mixto, introducido por la $\mathrm{LO} 5 / 2010^{40}$, hacia un modelo de autorresponsabilidad.

${ }^{38}$ GÓMEZ-JARA DÍEZ, C., «La responsabilidad penal de las personas jurídicas en la reforma del Código Penal», Diario La Ley, versión electrónica, $\mathrm{n}^{\circ} 7534$, 20IO, págs. 5 ss.; NIETO MARTÍN, A., «La responsabilidad penal de las personas jurídicas tras la LO 5/20I0», en Revista Xurídica Galega, nº. 63, 2009, págs. 55 ss.; ZÚÑIGA RODRÍGUEZ, L., «El sistema de sanciones penales aplicables a las personas jurídicas», en BERDUGO GÓMEZ DE LA TORRE, I. (coord.), Lecciones y Materiales para el estudio del Derecho Penal, Tomo I, Madrid, Iustel, 20I0, pág. 3i6; MORALES PRATS, F., «La responsabilidad penal de las personas jurídicas, artículos 3I bis, 3I.2, 33.7, 66 bis, I29, I30.2 CP», cit., págs. 55 y 56; entre otros.

${ }^{39}$ Que determina la posibilidad de exigir responsabilidad a las personas jurídicas aun cuando la concreta persona física responsable no haya sido individualizada o no haya sido posible dirigir el procedimiento contra ella, la incomunicabilidad de las circunstancias que afecten a la culpabilidad de la persona física o agraven su responsabilidad y la responsabilidad de las personas jurídicas pese a que los individuos físicos hayan fallecido o se hubieren sustraído a la acción de la justicia.

${ }^{40}$ Como indicamos en DÍAZ GÓMEZ, A., «El modelo de responsabilidad criminal de las personas jurídicas tras la $\mathrm{LO}$ 5/20IO», cit., págs. 20 a 24 . 
Efectivamente, de acuerdo con la regulación que se pretende introducir, no se puede atender exclusivamente a los delitos cometidos en el ámbito de la persona jurídica, sino que podrá afirmarse que el delito cometido por parte de la persona física «constituye una condición objetiva de punibilidad, a partir de la cual debe investigarse el verdadero fundamento de la responsabilidad del ente, el defecto de organización ${ }^{4 \mathrm{~T}}$. Mientras que el sistema introducido por la LO 5/2010 no resulta plenamente satisfactorio, entre otras cosas porque al no tener en cuenta la culpabilidad de la persona jurídica el tenor de la norma impide excluir de responsabilidad criminal a las organizaciones con programas de prevención adecuados, la proyectada reforma del Código Penal busca superar adecuadamente estos inconvenientes.

\section{Bibliografía citada}

Alonso Gallo, J., «Los programas de cumplimiento», en Díaz-Maroto y Villarejo, J. (dir.), Estudios sobre las reformas del Código Penal, Cizur Menor, Aranzadi, 201 I.

BACHMAIER WINTER, L., «Responsabilidad penal de las personas jurídicas: definición y elementos de un programa de compliance», en Diario La Ley, n 7938, 2012.

BACIgAlUPo ZAPATER, E., «Responsabilidad penal y administrativa de las personas jurídicas y programas de 'compliance': a propósito del Proyecto de reformas del Código Penal de 2009», en Diario La Ley, versión electrónica, $\mathrm{n}^{\circ} 7442,2010$.

Broseta Pont, M. y Martínez Sanz, F., Manual de Derecho mercantil, vol.I, Madrid, Tecnos, 2008.

DíAZ GómEZ, A., «El modelo de responsabilidad criminal de las personas jurídicas tras la LO 5/20I0», en Revista Electrónica de Ciencia Penal y Criminología, no I8, $201 \mathrm{II}$.

— «La Responsabilidad Criminal de las Personas Jurídicas en el Derecho Español», en línea: www.epol.com.ar/newsmatic/index.php?pub_id=72I\&sid=6780\&NombreSeccion=Difusi\%F3n\&Acci on $=$ VerArticulo\&aid $=70043 \&$ eid $=\mathrm{I}$

Díez Ripollés, J.L., Derecho Penal Español. Parte General en esquemas, Valencia, Tirant lo Blanch, 2 OII.

— «La responsabilidad penal de las personas jurídicas. Regulación española», en InDret, $\mathrm{n}^{\circ}$ I, $20 \mathrm{I2}$.

— «Las penas de las personas jurídicas, y su determinación legal y judicial: regulación española», en FERNÁNDEZ TERUelo, J.G. (dir.), Estudios penales en homenaje al profesor Rodrigo Fabio, Oviedo, Constitutio Criminalis Carolina, 2013.

Dopico Gómez-Aller, J., «Presupuestos básicos de la responsabilidad penal del compliance officer y otros garantes en la empresa», en Actualidad jurídica Aranzadi, n 843, 2012.

Feijoo SÁncheZ, B., «Autorregulación y Derecho Penal de la empresa: ¿una cuestión de responsabilidad individual?», en ARRoYo JimÉnez, L., y NieTO MARTín, A. (dirs.), Autorregulación y Sanciones, Valladolid, Lex Nova, 2008.

— «La responsabilidad penal de las personas jurídicas», en Díaz-MARoto y Villarejo, J. (dir.), Estudios sobre las reformas del Código Penal, Cizur Menor, Aranzadi, 20 II.

GAllego DíAZ, M., «Las penas aplicables a las personas jurídicas en el Código Penal español», en Revista Penal, n 3I, 2013.

Gómez Tomillo, M., Introducción a la responsabilidad penal de las personas jurídicas en el sistema español, Valladolid, Lex Nova, 2010.

GómEZ-JARA DíEz, C., «Autoorganización empresarial y autorresponsabilidad empresarial: Hacia una verdadera responsabilidad penal de las personas jurídicas», en Revista electrónica de ciencia penal y criminología, $\mathrm{n}^{\circ}$ 8, 2006.

\footnotetext{
${ }^{41}$ NIETO MARTÍN, A., «La responsabilidad penal de las personas jurídicas tras la LO 5/20Io, cit., pág. 6I
} 
— «La responsabilidad penal de las personas jurídicas en la reforma del Código Penal», Diario La Ley, versión electrónica, $\mathrm{n}^{\circ}$ 7534, 2010.

- «Aspectos sustantivos relativos a la responsabilidad penal de las personas jurídicas», en Banacloche Palao, J., Zarzalejos Nieto, J. y Gómez-Jara Díez, C., Responsabilidad penal de las personas jurídicas: aspectos sustantivos y procesales, Madrid, La Ley, $20 \mathrm{II}$.

Guardiola Lago, M.J., Responsabilidad penal de las personas jurídicas y alcance del art. 129 del Código penal, Valencia, Tirant lo Blanch, 2004.

MAGRO SERVET, V., «Contenido necesario del plan de prevención jurídica de las empresas para evitar responsabilidades penales», en La Ley Penal, versión electrónica, $n^{\circ}$ 87, 20 II.

Manzanares Samaniego, J.L., «Comentarios a la reforma de la parte general del Código Penal conforme al nuevo anteproyecto de Ley Orgánica (y IV)», en Diario La Ley, versión electrónica, $\mathrm{n}^{\circ} 8003,2013$.

Mir PUiG, S. y AlCÁCER GUIRAO, R., «Cambio de orientación en la política criminal española: últimas reformas del código penal», en Gómez MARTín, V. (coord.), Política criminal y reforma penal, Madrid, Edisofer, 2007.

Morales Prats, F., «La responsabilidad penal de las personas jurídicas, artículos 3I bis, 3I.2, 33.7, 66 bis, I29, I30.2 CP», en Quintero Olivares, G. (dir.), La Reforma Penal de 2010: análisis Y comentarios, Cizur Menor, Aranzadi, 2010.

Muñoz Conde, F. y García ARÁn, M., Derecho penal Parte general, Valencia, Tirant lo Blanch, 2010.

- Derecho Penal. Parte especial, Valencia, Tirant lo Blanch, 2013.

Nieto Martín, A., La responsabilidad penal de las personas jurídicas: un modelo legislativo, Madrid, Iustel, 2008.

— «Responsabilidad social, gobierno corporativo y autorregulación: sus influencias en el derecho penal de la empresa Política Criminal», en Revista Electrónica Semestral de Políticas Públicas en Materias Penales, $\mathrm{n}^{\circ}$ 5, 2008.

— «La responsabilidad penal de las personas jurídicas tras la LO 5/20I0», en Revista Xurídica Galega, $n^{\circ} .63,2009$

ORTIZ DE URbina Gimeno, I., «Responsabilidad penal de las personas jurídicas y programas de cumplimiento empresarial ('compliance programs')», en GoÑ SEIN, J.L. (dir.), Ética empresarial y códigos de conducta, Madrid, La Ley, 20 II.

Orts Berenger, E. y GonzÁlez Cussac, J.L., Compendio de Derecho Penal. Parte General, Valencia, Tirant lo Blanch, 20I0.

Quintero Olivares, G., Parte General del Derecho Penal, Cizur Menor, Thomson Aranzadi, 20 oio.

- «La responsabilidad penal de los partidos como personas jurídicas», en Actualidad Jurídica Aranzadi, versión electrónica, $\mathrm{n}^{\circ}$ 859, 2013.

REAl Pérez, A. (coord.), Códigos de conducta y actividad económica, una perspectiva jurídica, Madrid, Marcial Pons, 2010.

RodotÁ, S., «Códigos de conducta: entre el hard law y el soft law», en REAL PÉREZ PÉREZ, A. (coord.), Códigos de conducta y actividad económica, una perspectiva jurídica, Madrid, Marcial Pons, 20IO.

RODRíGUEZ GARCíA, N., «Análisis de la regulación legal de la responsabilidad penal de las personas jurídicas en España», en NeIRA PeÑA, A. (coord.), Los retos del Poder Judicial ante la sociedad globalizada, A Coruña, Universidade da Coruña, 20II.

Zugaldía Espinar, J.M., «Artículo 3I», en Cobo Del, M. (dir.), Comentarios al Código Penal, tomo III, Madrid, Edersa, 2000.

— «Societas delinquere potest: análisis de la reforma operada en el Código Penal español por la LO 5/2010, de 22 de junio», en La ley penal, versión electrónica, n 76, 2010.

ZÚÑIGA RODRÍGUEZ, L., «El sistema de sanciones penales aplicables a las personas jurídicas», en Berdugo Gómez de La Torre, I. (coord.), Lecciones y Materiales para el estudio del Derecho Penal, Tomo I, Madrid, Iustel, 20 Io. 